\title{
Lymphoid enhancer factor 1 directs hair follicle patterning and epithelial cell fate
}

\author{
Pengbo Zhou, Carolyn Byrne, Jennifer Jacobs, and Elaine Fuchs ${ }^{1}$ \\ Howard Hughes Medical Institute, Department of Molecular Genetics and Cell Biology, The University of Chicago, \\ Chicago, Illinois 60637 USA
}

T cell-specific transcription factor (TCF-1) and lymphoid enhancer factor 1 (LEF-1) have been implicated exclusively in the regulation of $T$ cell-specific genes. The only adult tissue other than thymus known to express these factors is spleen and lymph node, which contain low levels of LEF-1 and no TCF-1. We noticed that genes involved in hair-specific gene expression possess LEF-1/TCF-1 consensus motifs located in similar positions relative to their TATA box. We show that of the two factors only LEF-1 is expressed in hair follicles; it can be cloned in both splice forms from human skin keratinocytes and it can bind to these sites in the hair promoters. We show that LEF-1 mRNA is present in pluripotent ectoderm, and it is up-regulated in a highly restricted pattern just before the formation of underlying mesenchymal condensates and commitment of overlying ectodermal cells to invaginate and become hair follicles. New waves of ectodermal LEF-1 spots appear concomitant with new waves of follicle morphogenesis. To test whether LEF-1 patterning might be functionally important for hair patterning and morphogenesis, we used transgenic technology to alter the patterning and timing of LEF-1 over the surface ectoderm. Striking abnormalities arose in the positioning and orientation of hair follicles, leaving a marked disruption of this normally uniform patterning. This provides the first direct evidence that ectodermal cues are critical in establishing these developmental processes, which at later stages are known to be influenced by underlying mesenchyme. Remarkably, elevated LEF-1 in the lip furrow epithelium of developing transgenic animals triggered these cells to invaginate, sometimes leading to the inappropriate adoption of hair follicle and tooth cell fates. Collectively, our findings demonstrate that ectodermal expression of LEF-1 plays a central role in gene expression, pattern formation, and other developmental processes involving epithelial-mesenchymal associations.

[Key Words: LEF-1; TCF-1; transcription factors; hair follicle morphogenesis; keratin gene regulation]

Received September 28, 1994; revised version accepted February 8, 1995.

T cell-specific transcription factor (TCF-1) and lymphoid enhancer factor (LEF-1) are recently isolated transcription factors that contain a DNA-binding sequence homologous to the high mobility group (HMG) motif, an $\sim 80$ amino acid domain conserved in the HMG proteins (Travis et al. 1991; van de Wetering et al. 1991). Both TCF-1 and LEF-1 contain a high degree of homology in their HMG domains, and both recognize the core consensus motif 5'-CTTTGA/TA/T-3', located in the enhancers of a number of genes expressed at early stages of T-cell development (Travis et al. 1991; van de Wetering et al. 1991; Waterman et al. 1991; Giese et al. 1991, 1992; Giese and Grosschedl 1993). Both factors exist in alternative splicing forms, but all forms bind to the same sequence, making the functional significance of this multiplicity unclear (Travis et al. 1991; van de Wetering et al. 1991, 1992).

All forms of TCF-1 and LEF-1 mRNAs have been detected in adult thymus and various T-cell culture lines, but not in other adult nonlymphoid tissues or non- $T$-cell

${ }^{1}$ Corresponding author. lines (Travis et al. 1991; van de Wetering et al. 1991; Waterman et al. 1991). During embryogenesis, TCF-1 and LEF-1 mRNAs are expressed more broadly and sometimes differentially (Oosterwegel et al. 1993). In the developing thymus, TCF- 1 is induced just before T cellspecific gene expression. On the other hand, LEF-1 mRNAs are expressed less abundantly and more uniformly throughout T-cell development, suggesting that its function might differ from that of TCF-1.

DNA binding by LEF-1 has been shown to involve an interaction with the minor groove, and it invokes a sharp bend in the DNA helix (Giese et al. 1991, 1992). It has been postulated that LEF-1 and TCF-1 may exert their effects by bringing other DNA-bound transcription factors closer to one another, thereby facilitating their association. Thus, these factors have been implicated in the structural modeling of chromatin, rather than functioning as conventional transcriptional activators. This said, non-HMG transcriptional activation has also been noted (Carlsson et al. 1993).

Our focus on LEF-1 began from an interest in the regulation of the genes involved in hair follicle morphogen- 
esis and differentiation. A number of genes have been cloned that encode hair-specific keratins, the major structural proteins of the hair shaft (Heid et al. 1986; for review, see Rogers and Powell 1993). Although little is known about the precise mechanisms underlying the regulation of any of these genes, a number of potential regulatory motifs have been identified on the basis of sequence comparisons (McNab et al. 1989; Powell et al. 1991, 1992; Rogers and Powell 1993). One of these sites, 5'-CTTTGAAGA-3', referred to as the HK-1 motif, was detected in four published hair keratin promoters (Powell et al. 1991; Rogers and Powell 1993). The similarities between the HK-1 sequence motif and the LEF-1/TCF-1 motif prompted us to explore the possibility that these transcription factors may be involved in regulation of hair morphogenesis and gene expression.

In this report, we show that LEF-1 motifs are present in 13 of 13 published hair keratin promoters, and that the motifs often reside between 180 and 250 bp $5^{\prime}$ from the TATA box. We show that LEF-1 binds hair keratin promoters in vitro, and that LEF-1 is present during skin development in ectoderm that will express these promoters as the cells differentiate. In addition, we show that LEF-1 concentrates at regions where underlying mesenchymal condensates will form and initiate epithelial-mesenchymal interactions prerequisite to hair follicle morphogenesis. To test the possibility that the patterning of ectodermally derived LEF-1 is involved functionally in the determination and morphogenesis of hair follicles, we engineered a transgene to misregulate the levels and timing of expression of LEF-1 during skin embryogenesis in mice. We show that these mice have gross abnormalities in the positioning and angling of their hair follicles, processes previously assumed, although never demonstrated, to be controlled by mesenchyme. Moreover, the elevated levels of LEF-1 seem to create confusion within the biochemical programs that allow oral epithelial cells to select their cell fates. In some cases, this results in an incorrect fate choice, leading to hairs and teeth protruding from inappropriate sites in the gums. Our findings have important implications for understanding hair and tooth development and the role of LEF-1 in these complex processes.

\section{Results}

Hair follicle differentiation and the widespread presence of LEF-1/TCF-1 motifs in hair keratin promoters

Epidermis, hairs, and nails are all derived embryologically from a common precursor, the ectoderm (Fig. 1; Hardy 1992). In the adult hair follicle, differentiation is complex (Fig. 1). The hair is surrounded by two sheaths, an outer root sheath contiguous with the epidermis but thought to have its own compartment of stem cells (Rochat et al. 1994), and an inner root sheath, whose cells are derived from the same precursors as the hair
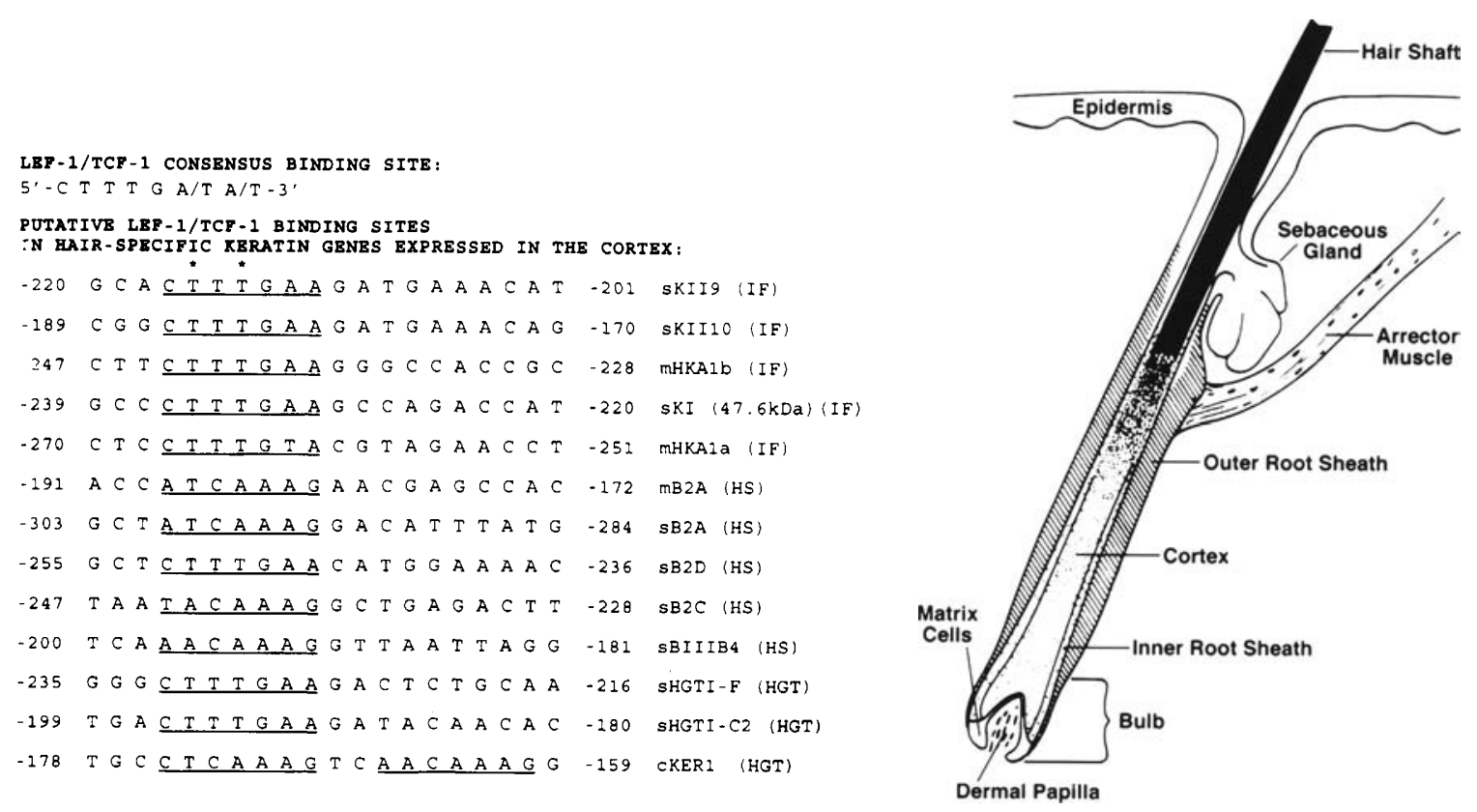

Figure 1. The program of hair follicle differentiation and the presence of LEF-1/TCF-1-binding sites in hair-specific genes. All published hair-specific promoters have a LEF-1/TCF-1 consensus motif positioned similarly relative to the TATA box. The mitotically active matrix cells form a bulb around specialized mesenchymal cells (i.e., dermal papilla). As they move upward, they become differentiating cortical cells, which begin to express the hair-specific keratin genes. The hair shaft cells are composed of keratin intermediate filaments (IFs), high sulfur (HS) and high glycine and tyrosine (HGT) keratins. Sequences are from GenBank (additional information in Powell et al. 1992; Rogers and Powell 1993). Asterisks denote mutations known to abolish LEF-1 binding (Waterman et al. 1991). 
shaft. The determination and differentiation of each hair is controlled by specialized mesenchymal cells, referred to as the dermal papilla. Dermal papilla cells transmit their signals to the epithelial precursors of the hair, or matrix cells, which are relatively undifferentiated epithelial cells surrounding the dermal papilla. A molecular understanding of these interactions remains largely obscure. In their mitotically active state, matrix cells maintain close association with the dermal papilla. As they move upward and away from this compartment, they cease to divide and begin to differentiate. The postmitotic cortical cells are the precursors of the hair shaft whose cells are composed of keratin intermediate filaments (IFs), sealed together by high sulfur (HS) and high glycine and tyrosine (HGT) keratins. The cortex is the first stage of terminal differentiation where the hair-specific genes are expressed (Kopan and Fuchs 1989; Powell et al. 1991; Rogers and Powell 1993).

Thirteen hair-specific keratin promoters have been sequenced (for review, see Rogers and Powell 1993). In scanning these sequences, we discovered that all harbor a LEF-1/TCF-1 motif (Fig. 1). Interestingly, for all these genes, the first such motif is positioned similarly, 160 $300 \mathrm{bp} \mathrm{5}$ from the TATA box. In one case where $3688 \mathrm{bp}$ of mouse hair keratin promoter sequence is known (Kaytes et al. 1991), there are six putative LEF-1-binding sites, each sharing $100 \%$ identity with the core sequence. As is typical of the optimal LEF-1-binding site (Giese et al. 1992; Giese and Grosschedl 1993), there is often a C preceding the consensus, and A's instead of T's at the $3^{\prime}$ end.

\section{LEF-1 $m R N A$ and protein are present in cultured human skin keratinocytes and in hair follicles}

The widespread occurrence of the LEF-1/TCF-1 sequence motif led us to wonder whether one of these factors might play a prominent role in hair follicle gene expression. To determine whether LEF-1 or TCF-1 mRNA, or both, are expressed in human skin, we isolated total RNAs from cultured human skin keratinocytes and from plucked hair follicles. After transcribing the mRNAs into cDNAs, we conducted PCR analyses using (1) a primer set that could distinguish between the two known splice variants of LEF-1 or (2) a primer set that encompassed a region common to all of the known variants of TCF-1. Figure 2 shows that both LEF-1 splice variants were detected in the RNA samples from skin keratinocytes and from hair follicles. In contrast, a primer set spanning the segment common to all TCF-1 forms produced the expected PCR fragment in T-lymphocyte cDNAs, but we were unable to detect this band in skin keratinocyte or in hair follicle cDNAs. Therefore, of the two, LEF-1 seemed to the best candidate to be functionally important in the follicle.

We isolated and cloned both LEF-1 splice variants from full-length PCR fragments of human skin keratinocyte cDNA. The sequences (not shown) were indistinguishable from the LEF-1 splice forms cloned from human $T$ cells (Waterman et al. 1991). To verify unequivocally the existence of LEF-1 mRNA in developing mouse hair follicles, we conducted RNase protection assays (Fig. 3). A 510-nucleotide radiolabeled LEF-1 antisense cRNA was used as probe (lane 1). Hybridization of this probe with synthetic full-length LEF-1 mRNA resulted in the formation of a 489-bp RNA-RNA hybrid that was protected from subsequent RNase digestion (lane 3). When this experiment was repeated with total skin RNA of E18.5 embryos and of mice at ages 2 days, 5 days, and 2 weeks, a 459-nucleotide fragment was protected (lanes 6-9). This fragment was diagnostic for endogenous LEF-1 mRNA, and was detected in an RNase protection assay from spleen RNA (lane 5), but not from liver RNA (lane 4). These findings confirmed that bona fide LEF-1 mRNA is present in the skin of mice, both embryologically and postnatally. Although the RNA samples we examined included both epidermis and hair follicles, the LEF-1 mRNA of postnatal skin came only from the hair follicles (see below).

To verify that the LEF-1 mRNA that we detected was translated in vivo, we conducted immunoblot analysis of nuclear proteins extracted from the skin of a 2-day-old mouse (Fig. 4). An anti-LEF1 antiserum cross-reacted with a major $54-\mathrm{kD}$ protein, which was detected in mouse skin and in cultured human skin keratinocytes (lanes 1 and 2, mouse skin; lane 5, skin keratinocytes). A band of this size was also detected in the Jurkat lymphoma T-cell line known to contain LEF-1 and to crossreact with this antisera (lane 4). The lower band in the Jurkat and epidermal nuclear extracts represents the short splicing form of LEF-1, which is only present in human and not in mouse cells (Giese et al. 1991; Waterman et al. 1991). These data indicate that LEF-1 mRNA
Figure 2. Detection of both mRNA splice forms of human LEF-1, but not of TCF-1, in cultured skin keratinocytes and in hair follicles. RNAs were isolated from cultured Jurkat lymphoma $T$ cells $(T)$, cultured skin keratinocytes $(E)$, and plucked scalp follicles $(H)$. Reverse-transcribed cDNAs were PCR amplified using primer sets specific for either LEF- 1 and LEF- $1^{*}(a$; the shorter splice form $)$, or a region common to all TCF-1 splice forms $(b)$. PCR products were resolved by agarose gel electrophoresis and visualized by ethidium bromide staining. Fragments were of the expected sizes, and were cloned and sequenced to verify their identity. b
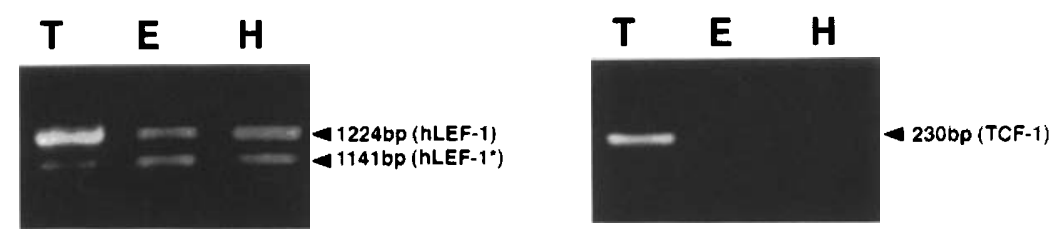


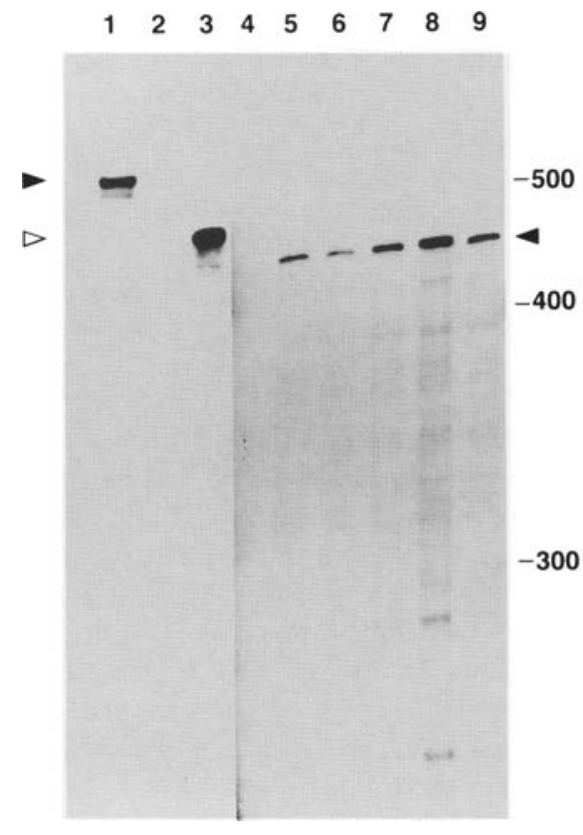

Figure 3. Detection of LEF-1 mRNA in the developing mouse skin by RNase protection assay. RNAs (20 $\mu$ g each) from yeast, mouse skin, mouse liver, and mouse spleen, as well as recombinant mouse LEF-1 mRNA (1 $\mu \mathrm{g})$, were hybridized with a ${ }^{32} \mathrm{P}$ labeled LEF-1 cRNA probe, followed by digestion with 0.5 unit of RNase A and 20 units of RNase T1 for $30 \mathrm{~min}$ to remove single-stranded RNAs. Protected LEF-1 mRNA fragments were separated on a $6 \%$ polyacrylamide-urea gel, which was exposed subsequently to X-ray film. (Lane 1) Free LEF-1 cRNA probe without RNase treatment. (Lanes 2-5) Protected fragments from RNAs of yeast (lane 2); recombinant LEF-1 (lane 3); liver (lane 4); spleen (lane 5). (Lanes 6-9) Protected fragments from skin RNAs of an 18.5-day-old embryo, and 2 day, 5 day, and 2-week-old mice, respectively. Exposures for lanes 4-9 was 2 days and for lanes 1-3 was $1 \mathrm{hr}$. The migration and size (in nucleotides) of $\left[{ }^{32} \mathrm{P}\right]$ UTP-labeled RNA standards are indicated at right. Arrowheads denote the position of undigested 510-nucleotide LEF-1 probe (solid arrowhead at left), or the 489-nucleotide LEF-1 fragment protected by recombinant LEF-1 mRNA /open arrowhead at left), or the 459-nucleotide fragment protected by endogenous RNA from various tissues (solid arrowhead at right).

and protein are expressed in embryonic and postnatal mouse skin and cultured keratinocytes.

\section{Expression of the LEF-1 splice variants in bacteria and electrophoretic mobility shift assays}

We cloned both splice forms of keratinocyte-derived human LEF- 1 cDNA into a pET-8c bacterial expression vector that produced LEF-1 as an amino-terminally, FLAG epitope-tagged protein. Protein extracts enriched for each recombinant LEF-1 variant were purified partially, and used in electrophoretic mobility-shift assays (EMSAs) with oligomers from two different hair gene promoters.

As shown in Figure 5, the full-length splice form of
LEF-1 bound to radiolabeled DNA fragments encompassing the putative LEF-1-binding sites of two promoters, sKII9 and sKIIl0, encoding hair keratins of the IF type. The smaller splice form of LEF-1 also bound effectively to both of these sites (data not shown). In this assay, the two splice forms behaved identically. Both types of complexes were specifically competed with cold competitor DNA, but not with analogous DNAs containing mutagenized LEF-1-binding sites (Fig. 5). Conversely, recombinant LEF-1 did not bind DNA fragments that contained the mutated LEF-1 site (data not shown; for mutations engineered, see asterisks in Fig. 1). Thus, the putative LEF-1-binding sites of at least two, and presumably most, hair promoters were bona fide motifs capable of binding purified LEF-1.

\section{LEF-1 is induced just before hair follicle development, continues throughout morphogenesis, and is prominent in the mitotically active cells of the mature follicle}

If LEF-1 is involved in controlling hair development or hair-specific keratin gene expression in vivo, then it should be expressed in the epithelial component of the hair follicles. To investigate this possibility, we cloned the mouse LEF-1 homolog from newborn backskin, and conducted in situ hybridizations on whole mouse embryos (Fig. 6). Recently, we devised conditions that enable us to examine the expression of mRNAs over the surface of mouse embryos as old as E15.5 (Byrne et al.

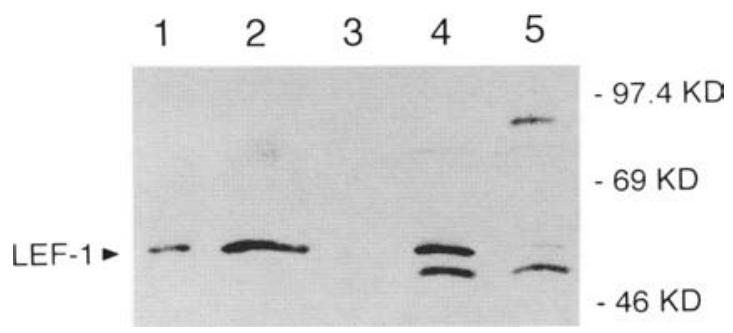

Figure 4. Detection of LEF-1 protein in mouse skin. Nuclear extracts were prepared from mouse skin (Trepicchio et al. 1994) or cultured Jurkat lymphoma, HepG2 liver hepatocytes, or epidermal keratinocytes (Aneskievich and Fuchs 1992). Protein levels were verified by SDS-PAGE and Coomassie Blue staining, and equal amounts of extracts were then fractionated by SDSPAGE, and transferred to nitrocellulose by electroblotting. LEF-1 protein was detected by an anti-LEF-1 rabbit polyclonal antiserum that had been preabsorbed by a hepatic nuclear protein blot at $4^{\circ} \mathrm{C}$ overnight to remove nonspecific antibodies, and then diluted $(1: 5000)$. Antibody binding was visualized using Enhanced chemiluminescence (Amersham Life Science, Buckinghamshire, UK). (Lanes 1,2) Nuclear protein (10.6 and $23.5 \mu \mathrm{g}$, respectively) isolated from skin of a 2-day-old mouse. (Lanes $3-5$ ) Extracts (23.5 $\mu \mathrm{g}$ each) from HepG2, Jurkat, and epidermal keratinocytes, respectively. The arrowhead indicates the $54-\mathrm{kD}$ LEF1 protein of mouse or human. The lower band is the splicing variant of LEFI observed in Jurkat and epidermal nuclear extract, but not in mouse hair follicles. The numbers on the right are sizes of molecular mass standards. 


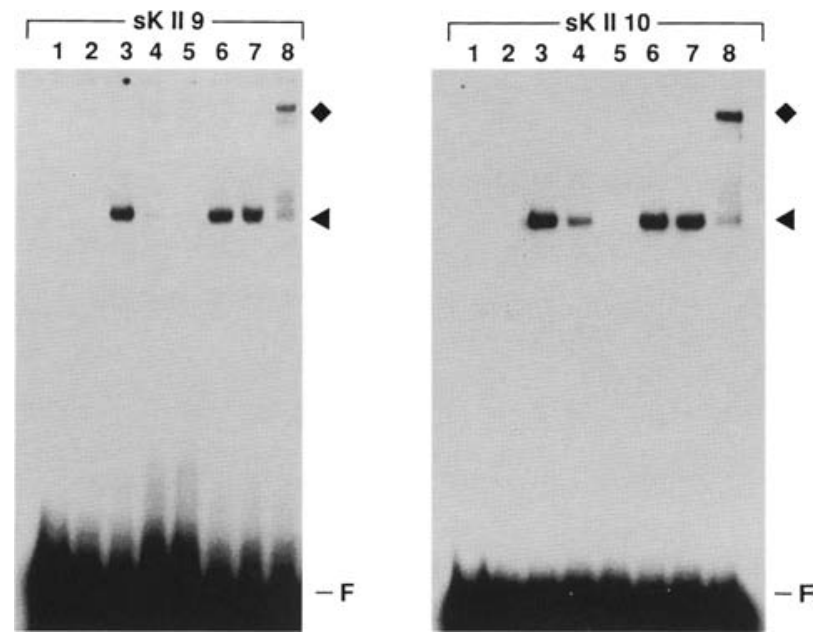

Figure 5. LEF-1 binds to hair keratin promoters. Electrophoretic mobility-shift assays (EMSAs) were conducted with recombinant LEF-1 and ${ }^{32}$ P]dCTP-labeled oligomers (30 bp) encompassing the LEF-1-binding sites of the sKII9 and sKIIIO hair keratin promoters. To make recombinant LEF-1, a BglII-BamHI fragment encoding all but the first 35 amino acids of human LEF-1 was linked in-frame 3 ' to a NcoI-BgIII fragment containing the FLAG epitope tag and inserted into the pET8c bacterial expression vector. Bacteria were transformed, and recombinant protein was then purified partially as described previously (Zhou et al. 1992). EMSAs were performed in triplicate (Aneskievich and Fuchs 1992). (Lane 1) Free probe; (lane 2) protein $(5 \mu \mathrm{g})$ from pET8c (vector alone) transformed bacteria; (lane 3) protein $(5 \mu \mathrm{g})$ from FLAG-LEFl transformed bacteria; (lanes 4-5) same as lane 3 , but with $20 \times$ and $100 \times$, respectively, of specific competitor; (lanes 6,7) same as lane 3 , but with $20 \times$ and $100 \times$ mutant competitor; (lane 8) same as lane 3, but with 0.3 $\mu \mathrm{g}$ of FLAG antibody (Eastman Kodak Co., Rochester, NY). Complex is indicated by an arrowhead; antibody-mediated supershifting complex is denoted by a diamond; $(F)$ free probe. Mutant competitors had A mutations in the first and third $T$ residues of the sKII9 and sKII10 LEF-1-binding sites (asterisks in Fig. 1).

1994). LEF-1 cRNA was present at E11.5 (not shown) and E12.5 (Fig. 6A), in the whisker pad region, in the follicles above and below the eye, and in a few other spots /denoted by arrows) where hair follicles are known to develop precociously (van Exan and Hardy 1990). As judged by in situ hybridization with a cRNA probe to one of the earliest expressed hair-specific keratin genes, no hair keratins were expressed at this early stage (Fig. 6B). One day later, hair-specific keratin gene expression was still silent, whereas a pattern of LEF-1 cRNA hybridizing spots appeared over most of the body (Fig. 6C). This expression was concomitant with the earliest known biochemical signals of immature body follicles, and it preceded morphological signs (Sengel 1976; Hardy 1992; Byrne et al. 1994). As development proceeded, the patterns of hybridizing spots became progressively denser, coincident with the staggered waves of follicle morphogenesis known to occur throughout these stages. At each developmental stage, the new spots of LEF-1 appeared at the interstices of hexagons centered about the old spots. Figure 6, D and D' shows sections of the body surfaces of E14.5 and E15.5 embryos, taken at the same magnification to illustrate this increase in spot density. From these photographs, one can see the hexagonal pattern of LEF-1 hybridization surrounding the stronger spots of LEF-1 expression in the ectodermal placodes. In all cases, control embryos hybridized with sense LEF-1 cRNA probes were completely negative (not shown).

Sectioning of the hybridized embryos revealed the presence of LEF-1 expression throughout, although not homogeneously, in the ectoderm, which is still pluripotent at this stage (Fig. 6E; brackets denote intense spots of hybridization). The dense spots of LEF-1 hybridization seen on the skin surface of embryos (Fig. 6C, D) were also apparent in these sections (Fig. 6E). At E11.5, LEF-1 mRNA was primarily in the ectoderm. Soon afterward, condensates of mesenchymal cells formed under each of the dense ectodermal spots of LEF-1 hybridization, and this in turn seemed to lead to LEF-1 induction in these condensates. These condensates are the dermal papilla anlage known to appear just after the very early signs of placode formation and thought to play a major role in the initiation of follicle morphogenesis (Sengel 1976; Hardy 1992). The timing of LEF-1 expression in these zones appeared to take place just before initiation of follicle morphogenesis, since the epithelial cells had not yet begun their downward mode of migration.

As hair germ formation began, epithelial cells maintained contact with dermal papilla anlage and migrated inward (Fig. 6F, G). During this time, LEF-1 mRNA expression stayed with the invaginating tip of the developing hair follicle, explaining why in whole-mount in situ hybridizations, LEF-1 seemed to disappear from sites after $\sim 1-2$ days (cf., the whisker pads and follicles just over the eye in Fig. 6A, C). Throughout these early stages of embryogenesis, hair-specific keratin genes were not expressed, and whole-mount in situ hybridizations using the hair keratin cRNA remained negative. Interestingly, as morphogenesis proceeded, LEF-1 expression became strong in the developing dermal papilla, now encased by epithelium (Fig. 6H). To a lesser extent, hybridization was now seen in the surrounding mesenchyme. Thus, the intensity of LEF-1 hybridization seemed to shift from ectoderm to mesenchyme at these intermediate stages of development. This said, throughout development, expression was maintained in the epithelium.

By E14.5-E15.5, the first signs of hair-specific keratin gene expression appeared in the most mature follicles, beginning with expression in the vibrissae of the whisker pads, and following with expression in the pelage follicles. Intriguingly, expression of LEF-1 and hair-specific keratin mRNAs occurred in the same population of epithelial cells (Fig. 6I,J; shown are data for vibrissae at E15.5). This highly restricted zone of expression began near the tip of the follicle, and formed a spike extending upward into the region destined to become the cortex of the fully mature follicle. As each follicle reached this stage of maturity, this coordinate pattern of LEF-1 and hair-specific keratin gene expression appeared. In addi- 

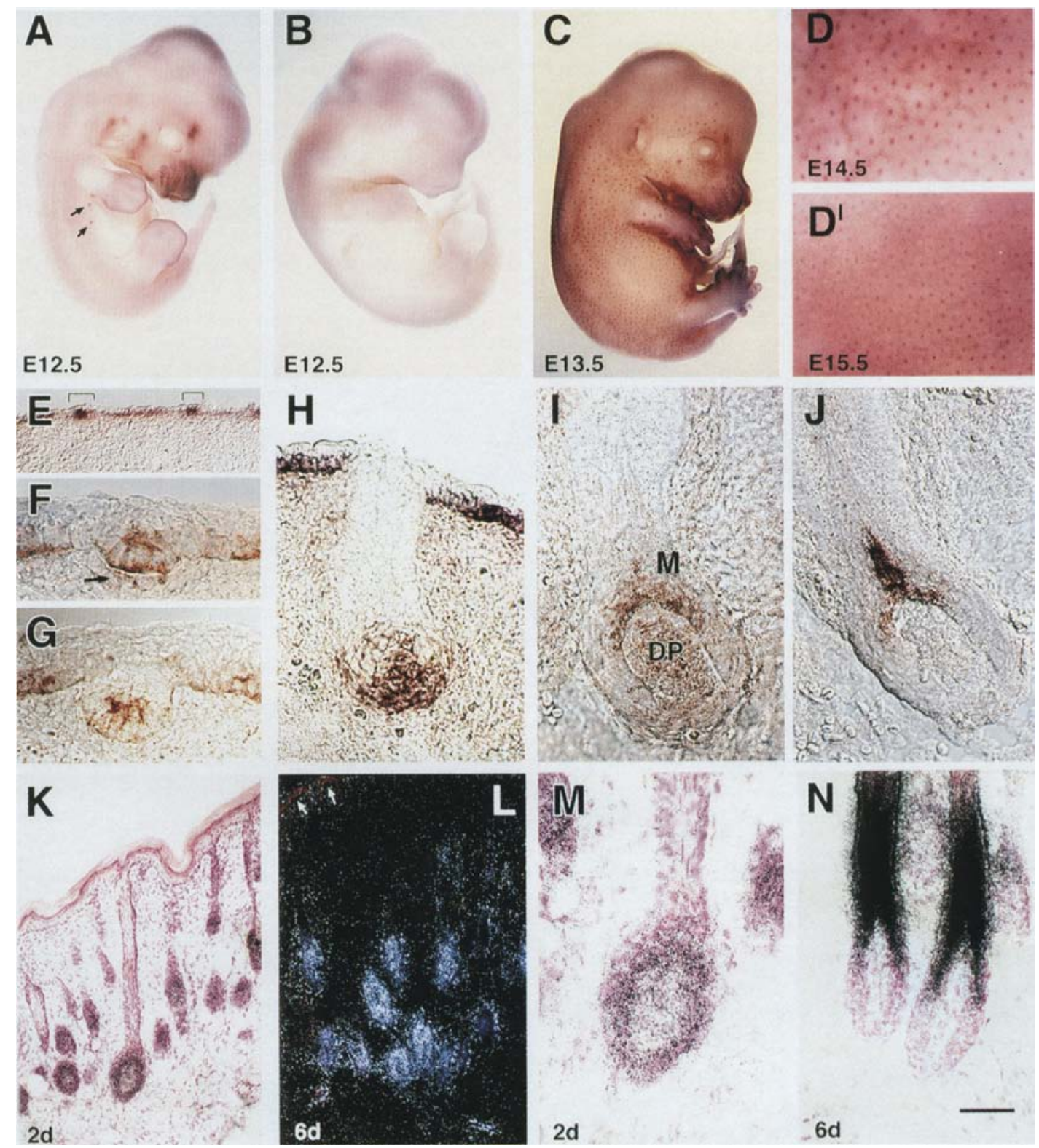

Figure 6. Expression of LEF-1 in developing hair follicles of mouse. Whole-mount and conventional in situ hybridizations were conducted using antisense (shown) and sense (not shown) LEF-1 and hair-specific keratin cRNA probes. Digoxygenin probes were used for whole-mount in situ hybridizations of mouse embryos, and probes labeled with ${ }^{35}$ S-labeled UTP were used for hybridizations of frozen skin sections of postnatal mice. $(A)$ LEF-1 cRNA hybridization at E12.5. Note hybridization to whisker pad, supraorbital and suborbital follicles, and a few precocious body follicles (arrows). (B) Hybridization of an E12.5 embryo with a cRNA probe against a type I intermediate filament hair-specific keratin mRNA, known to be expressed in the cortex of mature follicles. Note the absence of expression at this stage. $|C|$ LEF-1 expression at E13.5. Note that hybridization has disappeared around the whisker pad surface but now appears as spots over the body surface. $\left(D, D^{\prime}\right)$ Higher magnification photographs of the skin surface of E14.5 and E15.5 embryos. The same magnification was used for $D$ and $D^{\prime}$ to illustrate the progressive increase in density of LEF-1 hybridizing body surface spots that is coincident with new waves of follicle morphogenesis at these ages. $(E-H)$ Frozen sections of LEF-1 cRNA hybridized embryos showing LEF-1 expression in follicles of increasing maturity. In $E, F$, it can be seen that the body spots of increased LEF-1 hybridization correspond to immature follicle placodes, which associate with underlying mesenchymal condensates, the dermal papilla anlage (arrow in $F$ ). $(F-H)$ As the follicle matures and invaginates into the dermis, LEF-1 continues to be expressed in those cells maintaining contact with the inwardly migrating dermal papilla anlage. This results in a loss of follicle surface expression of LEF-1. (I-J) E15.5 vibrissae follicles of comparable maturity hybridized with LEF-I cRNA (I) or hair keratin cRNA (J). (M) Matrix; (DP) dermal papilla (in I). Note that this early expression pattern of hair keratin mRNA parallels that of LEF-1 mRNA in the matrix. (K-M) Postnatal skin sections hybridized with LEF-1 cRNA. Note the presence of LEF-1 grains in the matrix and dermal papilla of mature hair bulbs. ( $N$ ) Postnatal skin sections hybridized with a hair keratin cRNA showing expression predominantly in the cortex of mature follicles. Note: In all cases, sense cRNA controls showed only background hybridization. Embryonic ages are as indicated: (E) embryonic; (d) days after birth. Bar in $N$ represents $80 \mu \mathrm{m}$ in $E ; 30 \mu \mathrm{m}$ in $F-I ; 100 \mu \mathrm{m}$ in $K$ and $L$; and $50 \mu \mathrm{m}$ in $M$ and $N$. 
tion, LEF-1 continued to express in the developing dermal papilla cells, which do not express hair-specific keratin genes. The role for the LEF-1 in the mesenchymal compartment of the follicle was not further explored in this present study.

Within several days after birth in rodents, the first wave of developing body hair follicles have hair shafts that break the skin surface (Hardy 1992). In these maturing follicles, LEF-1 mRNAs concentrated primarily in the mitotically active matrix cells and in the dermal papilla now engulfed by the hair bulb (Fig. $6 \mathrm{~K}-\mathrm{M}$ ). In contrast, hair-specific keratin mRNAs were most abundant in cells that had committed to differentiate terminally and that had moved upward into the cortex compartment of the follicle (Fig. 6N). Thus, LEF-1 expression is clearly maintained in the mature follicle, but precedes the robust enhancement of expression of the myriad of hair-specific keratin genes that contain LEF-1-binding sites.

Previous investigators using conventional in situ hybridization methods had noted the expression of LEF-1 in embryonic skin mesenchyme (Oosterwegel et al. 1993; van Genderen et al. 1994). The ectodermal expression in developing follicles was not noted in these earlier studies, but could have been missed if sections were not taken directly through the base of the hair germs, or if follicles were sampled at a stage of development similar to that shown in Figure $6 \mathrm{H}$. The striking patterning of LEF-1 over the embryo surface is also a novel finding. Finally, it has been assumed that no adult tissues other than those of lymphoid origin express LEF-1 (Oosterwegel et al. 1993), but our studies here clearly indicate that postnatal, mature hair follicles do express this gene. When taken together with our finding of LEF-1-binding sites in a multitude of hair-specific genes, the presence of LEF-1 in the hair precursor cells (i.e., matrix) is likely to be an important feature of LEF-1 expression in skin.

\section{Functional evidence that LEF-1 is involved in hair morphogenesis and development}

The timing and expression pattern of LEF-1 mRNA during embryonic skin development suggested that the upregulation of LEF-1 in pluripotent ectoderm may be important in hair follicle patterning and development. To test this hypothesis, we engineered a transgene containing $2.5 \mathrm{~kb}$ of $5^{\prime}$ upstream sequence of the human K14 gene to elevate the expression of human LEF-1 cDNA in the ectoderm of mice. This promoter does not respond strongly to LEF-1 in chloramphenicol acetyltransferase (CAT) assays (data not shown), and in mice, it can stimulate $\beta$-galactosidase transgene expression potently in a fashion that faithfully mimics that of the endogenous K14 gene (Vassar et al. 1989; S. Zinkel and E. Fuchs, unpubl.). During embryonic development, the human $\mathrm{K} 14$ promoter is first activated in ectoderm at E9.5, and it is elevated dramatically by E14.5 in embryonic basal cells at a time when the second wave of hair follicle morphogenesis is just beginning. In developing hair germs, the promoter is not active in dermal papilla or in the epithelial cells at the tip of the developing follicle, but rather it is expressed in the cells that will ultimately become the outer root sheath (ORS) of the mature follicle (Kopan and Fuchs 1989; Byrne et al. 1994; S. Zinkel and E. Fuchs, unpubl.). Thus, although the promoter is active in skin development, its pattern and level of expression is strikingly different from that of LEF-1.

Of a total of 53 mice, 9 were scored by PCR analysis as positive for the transgene. Of these, five showed no apparent phenotype, one died shortly after birth, and three survived and displayed the phenotype shown in Figure 7A. These animals had hairs that broke the skin surface
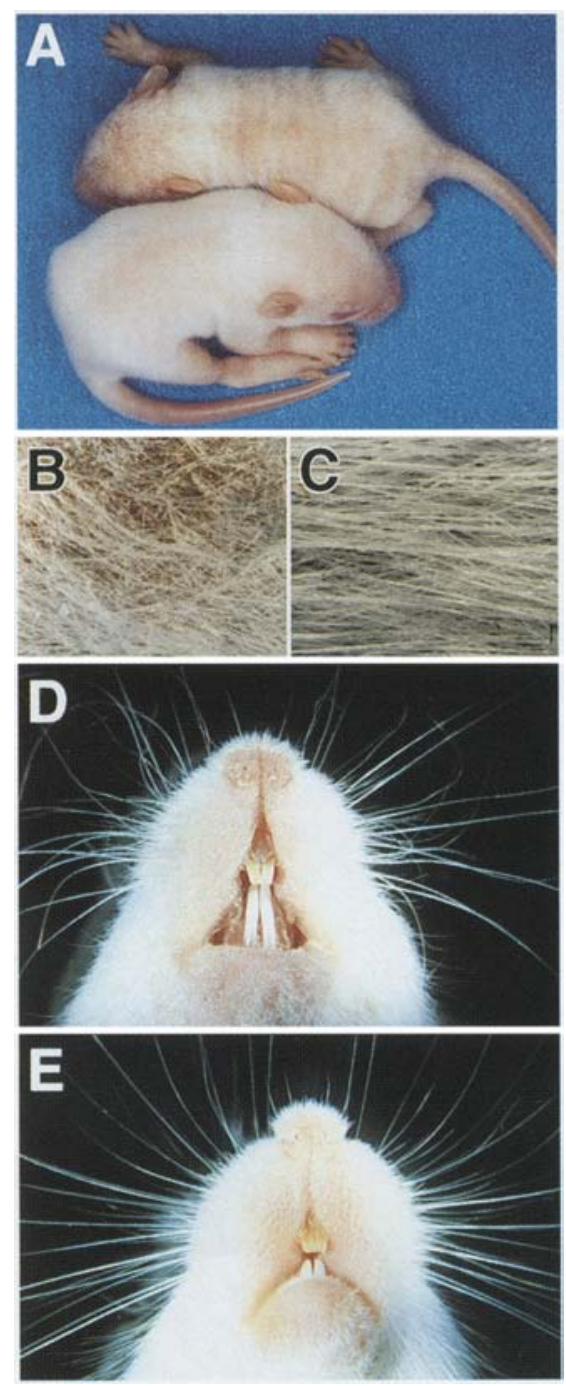

Figure 7. Transgenic mice expressing K14-LEF1 have alterations in their hair coat and whiskers. (A) A 7-day-old K14-LEF1 mouse (top) and a wild-type littermate. Note what appears to be sparseness of transgenic hair coat. $(B, C)$ Closer inspection of the backskin hair coat reveals misoriented hair shafts in a 4-weekold K14-LEF1 mouse $(B)$ in comparison to the uniformly oriented hairs of its wild-type littermate $(C) .(D, E)$ Vibrissae of whisker pads are curved and often oddly angled in a 4-week-old K14-LEF1 mouse $(D)$, relative to its control $\{E)$. 
in peculiar orientations, giving the hair coat a notably rough appearance (Fig. $7 \mathrm{~B}$ ). The coat of the transgenic mice had an overall sparse appearance. The sparse appearance of the coat seemed to be attributable, at least in part, to an aberrant patterning of hairs on the body surface. In contrast, normal animals display a spatial arrangement of follicles that is very precise and under strict developmental regulation (Fig. 7C). Finally, the whiskers of the transgenic animals were curly and often irregularly oriented relative to control animals (Fig. $7 \mathrm{D}, \mathrm{E}$, respectively). Collectively, these findings suggested that perturbations in hair development had taken place in the transgenic animals.

We first examined the histopathology of skin sections from our transgenic mice. Several very striking differences were observed (Fig. 8). As expected, follicles from the control littermates were uniformly spaced and aligned in parallel arrays relative to the skin surface (Fig. 8A). In addition, most of these follicles were at or nearing maturity, and a number of them had hair shafts even though they had not yet broken the skin surface. In contrast, the transgenic follicles were irregularly spaced and often tightly clustered (Fig. 8B,C). Moreover, follicles from newborn animals were often immature, and only a few had hair shafts. Often, these follicle structures were peculiarly angled relative to one another, perhaps reflective of their cramped spacing (Fig. 8C).

These remarkable differences in hair morphologies persisted throughout development. Thus, in skin sections of 4-week-old transgenic mice, many follicles were clustered together, whereas other regions showed gaps with no follicles (Fig. 8D). In a number of mice, the hair shaft from the second hair cycle was irregularly angled relative to the other (Fig. 8E). Follicles were often as much as $45^{\circ} \mathrm{C}$ off in their angling, and sometimes even crossed one another in the sections (Fig. 8F). Bulbs were often bent in addition to being irregularly angled relative to one another (Fig. 8F). Although many of the 28-day follicles had matured, the sizes of follicle bulbs were often variable. Serial sectioning indicated that whereas the skewed misangling of the follicles partially accounted for these variations, some of the follicles in the transgenic animals were not properly formed and were smaller than normal. Collectively, these features explained why the surface appearance of the fur coat of these transgenic mice was so peculiar.

A good correlation existed between the degree to which phenotypic abnormalities were observed in the transgenic animals and level of transgene expression. In neonatal mice, the activity of the K14 promoter persists in the basal layer of adult epidermis and in the ORS of hair follicle (Byrne and Fuchs 1993 and references therein). As judged by in situ hybridizations, LEF-1 mRNAs were inappropriately expressed at these places in postnatal skin (Fig. 9). For the highest expressors, the level of LEF-1 transgene mRNA in epidermis and ORS
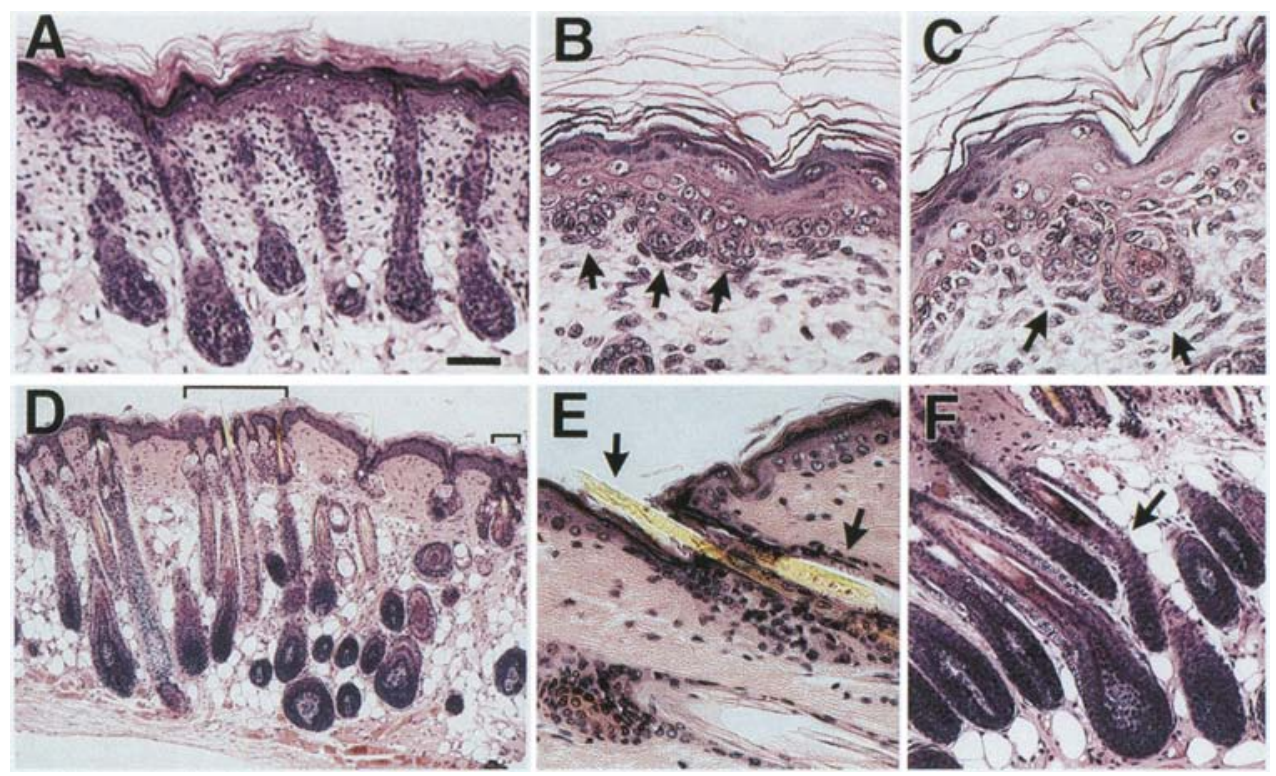

Figure 8. Histology of hair follicles from K14-LEFl transgenic mice. Sections $(5 \mu \mathrm{m})$ of skin from K14-LEF1 animals and control littermates were stained with hematoxylin and eosin. $(A)$ Backskin of a newborn control mouse. $(B, C)$ Backskin of newborn transgenic mouse. Follicles are irregularly clustered, and many appear rudimentary or developmentally retarded (denoted by arrows). (D-F). Skin samples of 4-week-old transgenic animal. (D) Region between eyes. Follicles are irregularly spaced, with some in clusters (large bracket). Other regions are devoid of follicles (region between brackets). Differences also exist in follicle maturity and in the irregular angling of follicles relative to skin surface. Small bracket denotes peculiar rudimentary structures. In backskin section (E), a new hair shaft emerges at an irregular angle (arrows), a feature typical of these mice. In $F$, two follicles are crossed and one is bent (arrow); follicles are generally in nonparallel orientations and in different sizes. Bar in $A$ represents $40 \mu \mathrm{m}$ in $A ; 20 \mu \mathrm{m}$ in $B$ and $C_{;} 120 \mu \mathrm{m}$ in $D ; 30 \mu \mathrm{m}$ in $E$; and $60 \mu \mathrm{m}$ in $F$ 


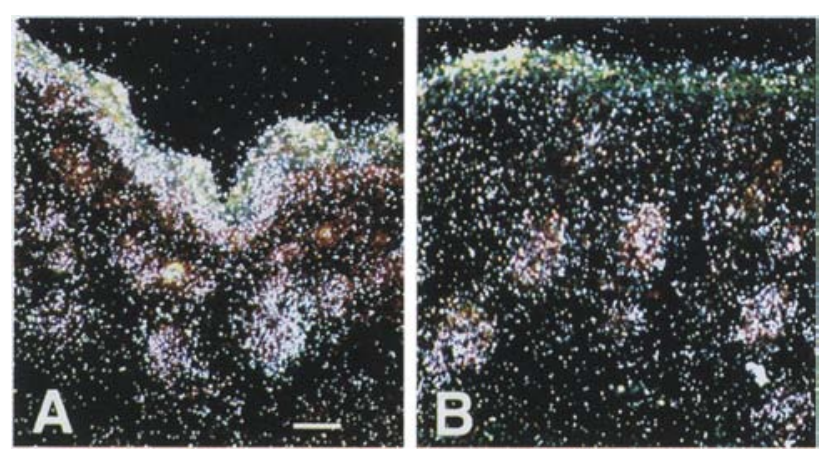

Figure 9. Aberrant expression of LEF-1 in K14-LEFl mice. Cryostat sections $(8 \mu \mathrm{m})$ of backskin from newborn K14-LEF1 transgenic and control littermates were hybridized with LEF1 or type I hair keratin cRNA probes labeled with ${ }^{35} \mathrm{~S}$-labeled UTP. After 5 days, they were processed and visualized by dark-field and bright-field light microscopy. Transgenic skin $(A)$ or control skin $(B)$ was hybridized with LEF1 cRNA probe. Note expression of LEF1 mRNA in the basal layer of epidermis and ORS of hair follicles in the neonatal transgenic skin. These cells do not normally express LEF1 but are permissive for K14 promoter activity. Bar, $50 \mu \mathrm{m}$.

seemed to be comparable to, if not greater than, that of endogenous LEF-1 mRNA in the matrix of follicles. The ectopic expression of LEF-1 in postnatal epidermis and ORS was not sufficient to induce hair-specific keratin gene expression in these cells, as evidenced by in situ hybridization with a hair-specific cRNA probe /data not shown). This finding was not surprising, but it did indicate that hair-specific gene expression was likely to be complex and dependent on multiple factors, as it is in most other tissues.

\section{Elevated expression of LEF-1 in oral epithelium can lead to redirection of cell fates}

Among the most surprising and unexpected features of the K14-LEF1 mice was the appearance of large hairs erupting from the gums, or gingiva, in the region derived from the lip furrow epithelium (Fig. 10A). Closer inspection revealed a number of smaller hairs in this region (Fig. 10B). Curiously, immediately adjacent to the site of the emergence of the two larger hairs of one animal was what appeared to be a rudimentary tooth, positioned at a completely inappropriate site. The inappropriate eruption of hairs and tooth-like structures in the oral epithelium suggested that dramatic perturbations in epithelial-mesenchymal interactions had taken place in this tissue.

The lip furrow epithelium begins as an epidermal thickening, which subsequently hollows out to form the oral vestibule between the lips and the gums. It is temporally and spatially related to the epithelium of the tooth bud, which like that of the hair germ, is dependent on mesenchymal-epithelial interactions. The presence and position of aberrant dental and hair appendages in the mouth of transgenic animals suggested to us that lip furrow epithelium might be a site of very high K14 and thus LEF-1 gene expression in these mice. In situ hybridizations using a K14 CRNA probe revealed that normal oral epithelium has marked K14 mRNA expression levels, and these levels are particularly strong in the thickened lip furrow (Fig. 11A,B). It was within this band of epithelium in the transgenic mouth that long hairs and tooth-like structures erupted (see Fig. 10).

Histological analyses of transgenic oral epithelia gave us a clue as to how LEF-1 expression in gum epithelium might be acting to influence morphogenetic processes involving epithelial-mesenchymal interactions. The epithelial lining of transgenic mouth seemed abnormal and contained numerous deep invaginations into the underlying mesenchyme. This was evident both on the mouth roof (Fig. 11D), and on the mouth floor (Fig. 11E). These invaginations appeared to be more frequent than in normal oral epithelium. Some of the invaginations were flat at the base, suggestive of the early stages of tooth development (Fig. 11E). Others more closely resembled hair germ formations, whereas others bore little relation to any primitive epithelial appendage (Fig. 11D-F). In some cases, well-differentiated structures resembling enamel organs and hair follicles could be seen in the oral epithelium at completely inappropriate positions (see Fig. 10). The odd angling of these appendages made it difficult to obtain good cross sections. However, overall, the number of invaginations was likely greater than the number of tooth or hair eruptions that we observed. When taken together, our findings suggest that elevated LEF-1 in epidermis and oral epithelium can trigger the formation of invaginations into the mesenchyme that are prerequisite to hair and tooth morphogenesis.
Figure 10. Inappropriate induction of tooth and hair morphogenesis in the mouth gums of mice expressing a K14-LEF-1 transgene. Representative example of aberrant tooth and abnormal hair formation in the gum area of a 4-week-old K14-LEF1 mouse. The bracket denotes the area of the gums, the arrow denotes the site of emergence of a rudimentary tooth and adjacent long hairs, and the arrowheads indicate the large hairs. Note also a number of smaller hairs in the gum area.
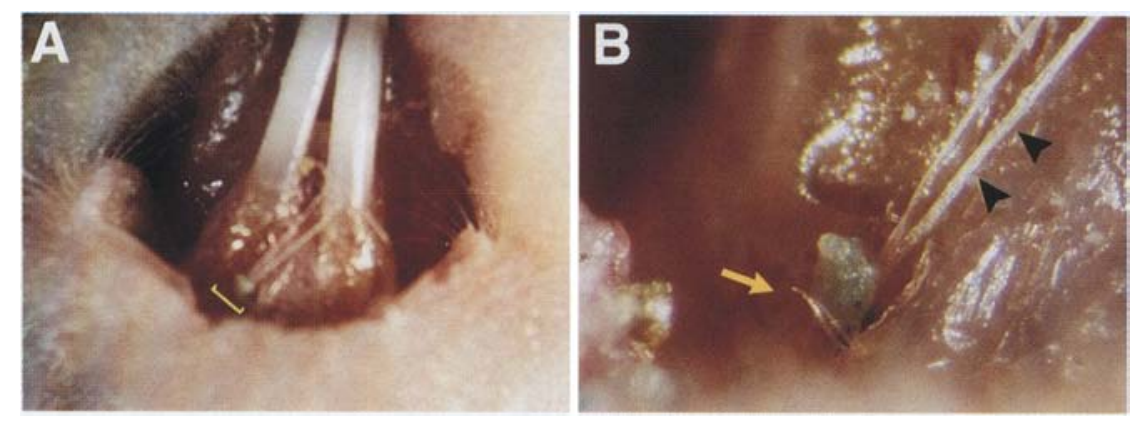


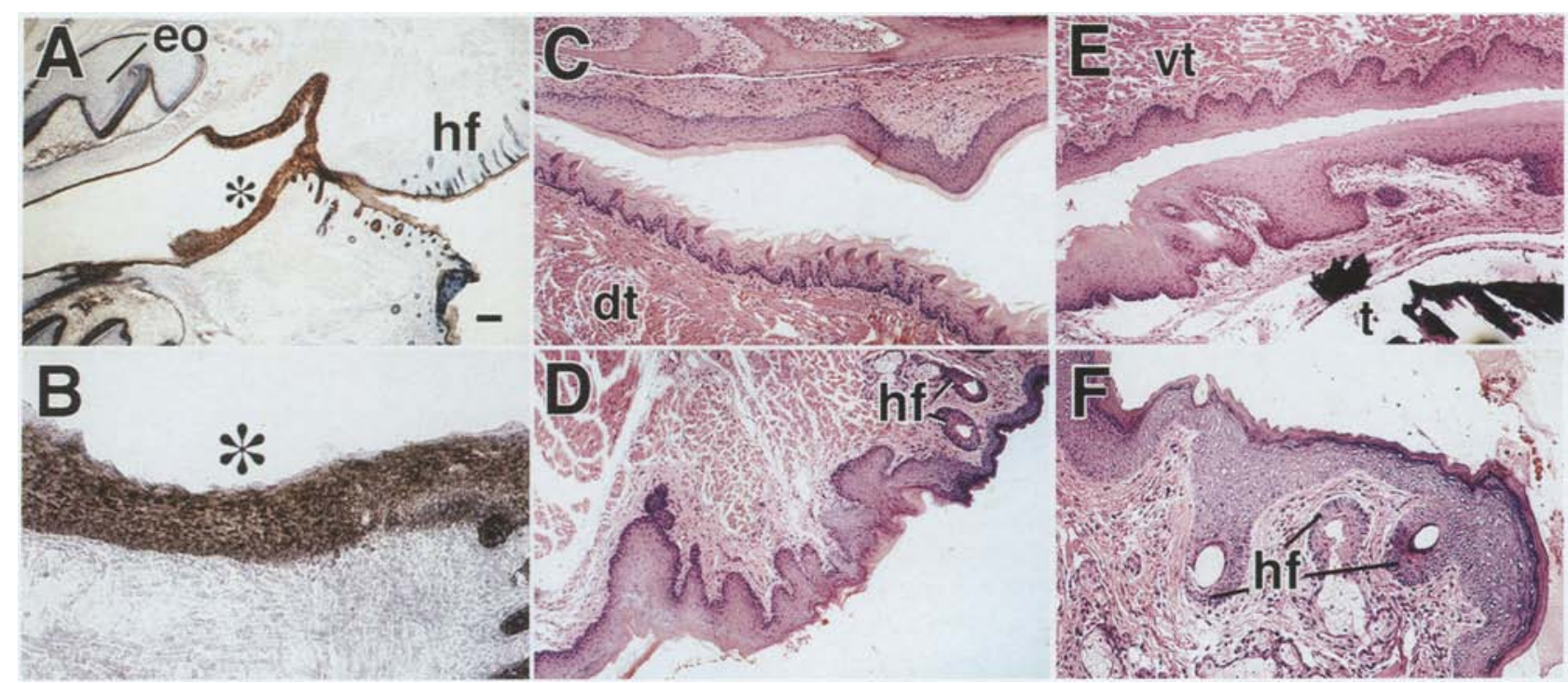

Figure 11. Histology of the oral epithelia of K14-LEF1 transgenic mouse. The head region of a 4-week-old K14-LEF1 transgenic and its wild-type control were submerged overnight in Bouins fixative, and then embedded in paraffin and sectioned sagittally. Sections $(5 \mathrm{\mu m} /$ were stained with hematoxylin and eosin. Another control animal was processed for in situ hybridization of mouth tissue sections with a radiolabeled K14 cRNA probe, followed by autoradiography and then counterstaining with toluidine blue. (A) K14 cRNA labeling of cross section of mouse head, revealing strong hybridization in lip furrow epithelium (asterisk) of mouth roof and floor. This region was magnified in $B .(C, D)$ Roof of the mouth of control $(C)$ and transgenic $(D)$ animals. Note epithelial invaginations in transgenic oral epithelium which seemed more numerous than in control, although some controls showed invaginations (not shown). Hair follicles (hf) indicate relative positioning of this section near the front of the mouth. $(E)$ Section of mouth floor of transgenic animal. $(F)$ Some invaginations resulted in the formation of hair follicles. Other invaginations resulted in formation of enamel organs, which were atypically positioned (not shown; see Fig. 10). (hf) Hair follicle; (dt) dorsal tongue; (vt) ventral tongue; $(\mathrm{t})$ incisor tooth. Bar in $A$ represents $250 \mu \mathrm{m}$ in $A ; 10 \mu \mathrm{m}$ in $B ; 67 \mu \mathrm{m}$ in $C-E_{;}$and $33 \mu \mathrm{m}$ in $F$.

\section{Discussion}

\section{LEF-1 and hair gene expression}

LEF-1 is the first nuclear factor shown to both be expressed in hair follicles and to possess binding sites in the broad spectrum of known hair-specific genes. A number of lines of evidence suggest that the action of LEF-1 at late stages of development involves at least in part the regulation of these genes: (1) LEF-1-binding sites are present in 13 of 13 published hair keratin promoters; (2) the LEF-1 site closest to the TATA box of each gene is positioned similarly, often at $\sim 180-250$ bp $5^{\prime}$ upstream from the TATA box; (3) in the only gene where substantial sequences $5^{\prime}$ upstream from the TATA box have been reported, six perfect LEF-1 sites exist within 3000 $\mathrm{bp}$; (4) LEF-1 binds to its consensus motifs in both of the hair promoters we tested; (5) two of the minimal hair promoters are stimulated by LEF-1 in CAT reporter gene assays of cultured skin keratinocytes, and this activation requires their functional LEF-1-binding sites (P. Zhou and E. Fuchs, unpubl.) (6) these two minimal promoters that contain LEF-1-binding sites are also sufficient to drive cortex-specific expression of a reporter gene in transgenic mice (McNab et al. 1990; Rogers and Powell 1993); and (7) LEF-1 mRNAs are in the right place at the right time to play a central role in hair morphogenesis and gene expression. Our discoveries that LEF-1-binding sites seem to be ubiquitous in hair promoters and that these sites are functional in vitro are particularly interesting in light of a recent report of LEF-1 knockout mice (van Gendereri et al. 1994), published while this manuscript was under revision, in which some follicles form, but they appear to lack the cortex and medulla (hair shaft), that is, the sites of hair keratin synthesis and storage, respectively.

LEF-1 does not appear to act as a conventional transcription factor, but rather by altering chromatin to create a structure conducive for conventional transcription factor binding (Giese et al. 1992). Intriguingly, many of the $T$ cell and hair genes are organized chromosomally in clusters, suggesting the possibility that LEF-1 (or in $\mathrm{T}$ cells, TCF-1) might be involved in activating chromatin over relatively long distances. This might enable LEF-1 to play a key role in controlling a large group of tightly linked, hair-specific genes. In addition, on the basis of the expression of LEF-1 predominantly in matrix rather than in cortex cells, it could be that LEF-1 is involved in creating a DNA structure needed for initiation, rather than maintenance, of hair-specific gene expression.

Thus far, the role of LEF-1 in gene regulation has only been assayed in transient transfections where transgenes are not likely to possess native chromatin structure. Furthermore, its role may be difficult to assess in transgenic cells or animals where the promoter may be out of context of its native chromatin structure. At the moment, there is no simple mechanism that can account for all of 
our data, a likely reflection of the complexities of gene expression in the follicle, where five to six different programs of differentiation can arise from the seemingly homogenous matrix cells. This said, the hair follicle is one of the few systems with spatially well-defined developmental and differentiation programs, and hence will be an important model in the future to sort out some of the remaining mysteries about this HMG protein.

\section{LEF-1 and hair morphogenesis: the importance of the ectoderm}

Given reports of previous investigators |Oosterwegel et al. 1993; van Genderen et al. 1994), we were surprised to discover that LEF-1 is expressed in the ectoderm. Ectodermal expression is first seen in spots overlying the sites where mesenchymal condensates will initiate epithelial invaginations and hair morphogenesis. With each wave of follicle morphogenesis, new spots of ectodermal LEF-1 are expressed at the greatest distance from the old LEF-1 spots. This up-regulation and patterning of LEF-1 represents one of the earliest biochemical changes known to take place in the epidermis. We also noted that LEF-1 expression is up-regulated in the mesenchyme as dermal papilla form and become encased by surrounding epithelium. We have not yet examined the functional significance of this finding. However, it is interesting that BMP2 and Msx2 genes show similar patterns of ectodermal and mesenchymal expression (MacKenzie et al. 1992; Vaino et al. 1993), and these factors could be involved in a similar pathway. These parallels merit future investigation.

Although it is well-established that mesenchyme is required for hair follicle morphogenesis, it has been a matter of controversy as to whether ectoderm or mesenchyme controls the positioning and orientation of follicles (Sengel 1976; Jahoda and Oliver 1984; for review, see Hardy 1992). Heterotypic mesenchyme-ectodermal recombination experiments in vitro and surgical manipulations of embryos in vivo have focused generally on the importance of mesenchyme in these processes. However, these studies do not explain why mutant ectoderm from scaleless or featherless chickens is not competent to form appendages when combined with wild-type mesenchyme (Sengel 1976). Studies with developing tooth germs, a related epithelial-mesenchymal process, have suggested that before E11, it is the oral epithelium of the mouse embryo that controls tooth morphogenesis, whereas after this time, control is transferred to mesenchyme (Mina and Kollar 1987). When taken together with our findings that LEF-1 is expressed in early ectoderm and in epithelial cells destined to express hair-specific keratin genes with LEF-1-binding sites, we propose that LEF-1 expression in the epithelium might be key to certain features of hair development.

Previously, we had shown that the K5 and K14 keratin promoters are active in embryonic ectoderm as early as E9.5, (i.e., preceding the first wave of hair follicle morphogenesis), and that they are up-regulated in embryonic basal cells by E14.5 (i.e., as the second wave of follicle morphogenesis initiates). Using the K14 promoter, we were able to up-regulate LEF-1 artificially throughout the ectoderm during skin development, and in particular at the onset of the second wave of hair follicle formation. This allowed us to disrupt the ectodermal patterning of LEF-1 expression and to test our hypothesis directly that misregulation of LEF-1 in the ectoderm might affect features of follicle development. Interestingly, we discovered that it is the early events (i.e., the spatial organization and orientation of the hair follicles) that are dramatically altered in our transgenic animals. During normal development, these features are controlled precisely, and waves of synchronously growing hair follicles sweep over the body at regular intervals. Our data provide the first in vivo test that changes in the epithelial component can influence these features of hair development. Moreover, they provide strong functional evidence that the patterning of LEF-1 in the early ectoderm is critical in influencing where, how, and at what angle the follicles will form.

When considered in light of these new findings, it is intriguing that LEF-1 may function to activate chromatin. Indeed, its expression seems to occur in ectoderm at a time when ectoderm is providing early cues to mesenchyme in controlling morphogenesis; its intensity of expression later shifts to mesenchyme at a time when mesenchyme is providing cues to ectoderm. These shifts in LEF-1 levels may be important reflections of changes in chromatin activity, a notion that we will pursue in future investigations.

The level of ectodermal LEF-1 can influence the fate of an epithelial cell

Perhaps the most striking feature of our transgenic mice was the inappropriate formation of follicles and toothlike structures in the oral epithelia, and particularly within the lip furrow. It is well-known that the lip furrow epithelium is temporally and spatially related to the incisor enamel organ, and that this epithelium can form teeth when placed in the presence of molar mesenchyme (Mina and Kollar 1987 and references therein). We have been able to achieve induction of enamel organogenesis without using heterotypic recombinations of isolated epithelial and mesenchymal tissues from various sources. Rather, we have engineered a single genetic change in the epithelium of the animals, which resulted in numerous epithelial invaginations into oral mesenchyme. Intriguingly, LEF-1-deficient mice show impairment of tooth formation (van Genderen et al. 1994), lending further support to the notion that tooth development, like hair morphogenesis, is dependent on this factor.

What is truly remarkable is that we were able to initiate morphogenetic pathways that were independent of the specificity of the underlying mesenchyme. The inappropriate differentiation of transgenic oral epithelium into hair follicles and enamel organs may explain why in normal animals, LEF-1 expression is turned off in neonatal ectoderm and presumably in other epithelia after appendage morphogenesis is completed. Further studies 
will be necessary to understand the precise molecular details of the steps involved; these studies suggest that a fine balance of timing and expression of LEF- 1 is necessary to direct properly epithelial-mesenchymal associations that precede invaginations of the epithelium and morphogenesis of its appendages.

When the results of the LEF-1 knockout mice are compared with those of the K14-LEF1 transgenic mice, both clearly demonstrate a functional importance of LEF-1 in hair and tooth development. However, because of the complexity of LEF-1 expression, the knockout does not provide evidence that LEF- 1 is involved directly, and it does not distinguish which cell types play a critical role in the process and how and when they do so. Our studies now provide critical positive evidence that LEF-1 is patterned in the ectoderm, and that ectodermally derived patterning of LEF-1 is critical to patterning of hairs and teeth. When taken together with our identification of ubiquitous LEF-1-binding motifs in the cell type-specific genes of the epithelial component of the hair follicle, and with our detailed study of LEF-1 expression in embryonic and adult hair follicles, our data provide dramatic new insights into our understanding of the complex roles of LEF-1 in hair follicle and tooth morphogenesis.

\section{Materials and methods}

\section{Cell culture}

Primary human epidermal keratinocytes were cultured as described previously (Wu and Rheinwald 1981). The human liver hepatocyte line HepG2 and Jurkat lymphoma T cells were obtained from the American Type Culture Collection (Rockville, MD) and cultured as described (Leask et al. 1990).

\section{$R T-P C R$ detection and cloning of hLEF-1 splicing variants}

Total RNA was isolated from cultured Jurkat lymphoma T cells and cultured skin keratinocytes as described (Kopan and Fuchs 1989). Human hair follicle bulbs were obtained by trimming 10-15 plucked scalp hair to the last $0.5 \mathrm{~cm}$, which contain the intact bulbs. Bulbs were examined by light microscopy and found to contain no exogeneous tissue. Trizol agent $(1 \mathrm{ml})$ (GIBCO BRL, Gaithersburg, MD) was added and RNA was extracted as suggested by the manufacturer. To synthesize the first strand cDNA, 5.0 $\mu \mathrm{g}$ of total RNA was reverse transcribed using $100 \mathrm{ng}$ of random hexamer primers (Pharmacia, Piscataway, NJ) as described in detail (Faus et al. 1994). Five microliters of each cDNA was used in PCR amplification under conditions specified by Perkin-Elmer Cetus (Norwalk, CT). The hLEF-1specific primers are 5'-ACA GCG GAG CGG AGA TTA CAG AGC-3' and 5'-TCA GAT GTA GGC AGC TGT CAT TCT GGG A-3'. The TCF-1 specific primers are 5 '-CGC CTT CAA TCT GCT CAT-3' and 5'-AGG TCA GGG AGT AGA AGC-3'. Amplified DNAs were extracted (Wizard kit, Promega Corporation, Madison, WI) and analyzed by electrophoresis through $1 \%$ agarose gels. Bands were visualized by ethidium bromide staining.

hLEF-1 (1.23 kb) and hLEF-1* (1.15 kb) DNA fragments from RT-PCRs of all three RNA samples were excised from the gel, electroeluted, purified, and subcloned into the PCRII TA cloning vector (Invitrogen, San Diego, CA) to make the plasmids pLEF-1 and pLEF- ${ }^{*}$. Cloned DNAs were subjected to DNA se- quencing to verify the identity of hLEF-1, hLEF-1 ${ }^{*}$, and Jurkat TCF-1 genes.

\section{RNA isolation and RNase protection assay}

Mouse liver and spleen total RNA were purchased from Clontech Laboratories (Palo Alto, CA). Mouse skin total RNA was prepared from 18.5-day embryos and from mice 2 and 5 days and 2 weeks postnatally (see Kopan and Fuchs 1989). Recombinant LEF-1 RNA was prepared using a pLEF-1 plasmid linearized by EcoRV and transcribed with T7 RNA polymerase. This RNA encompassed the complete LEF-1 open reading frame and a 30nucleotide plasmid sequence.

RNase protection assay was performed using the Ambion RPA II kit and conditions as recommended by the manufacturer with one exception: the hybridization was performed at $58^{\circ} \mathrm{C}$ overnight, instead of $45^{\circ} \mathrm{C}$. The template for preparing hybridization probe was made by digestion of the pLEF-1 plasmid with $N d e$ I to completion and purified by a $1 \%$ agarose gel. The $510-$ nucleotide hybridization probe (containing 459 nucleotides of 3 ' coding sequence of cloned LEF-1 RNA and 51 nucleotides of vector sequence) was synthesized by in vitro transcription using the Ambion SP6 MAXIscript system in the presence of $\left[{ }^{32} \mathrm{P}\right] \mathrm{UTP}$ (Amersham Corp., Arlington Heights, IL).

\section{Plasmids}

The epitope-tagged LEF-1 expression plasmid was constructed as follows: A BgIII-BamHI fragment encoding all but the first 35 amino acids of hLEF-1 was linked in-frame $3^{\prime}$ to an NcoI-BgIII fragment containing the FLAG epitope tag (Eastman Kodak Company, New Haven, CT) and inserted into the pET-8c bacterial expression vector (Novagen).

\section{Preparation of hybridization probes and in situ hybridization}

Digoxygenin hybridization probes were synthesizd according to the manufacturer's instructions (Boehringer Mannheim Biochemicals, Indianapolis, IN). ${ }^{35}$ S-labeled UTP probes were made as described (Kopan and Fuchs 1989). A 1217-bp mouse LEF-1 cDNA was amplified by PCR from newborn mouse skin RNA, and then cloned into plasmid pCRII (Invitrogen, San Diego, CA). Its identity was confirmed by sequencing. Antisense LEF-1 cRNA was made by linearizing the plasmid with EcoRV and transcribing with SP6 polymerase. Sense cRNA was made by linearizing with SpeI and then labeling with T7 polymerase. An 875-nucleotide type I hair keratin cRNA probe was made as described (Kopan and Fuchs 1989). An 1200-bp mouse K14 cDNA (gift of Jurgen Schweizer, Heidelberg, Germany) was subcloned into $\mathrm{KS}+$, linearized with EcoRI, and antisense cRNA was made using T3 RNA polymerase.

Whole-mount in situ hybridizations with digoxygenin probes were as described by Conlan and Rossant (1992), except that proteinase $\mathrm{K}$ treatments were optimized to preserve skin morphology without sacrificing penetration (Byrne et al. 1994). In situ hybridization of $8-\mu \mathrm{m}$ frozen tissue sections was carried out with cRNA probes labeled with ${ }^{35}$ S-labeled UTP as described (Kopan and Fuchs 1989), with some modifications (Novagen Inc, Madison, WI), or with digoxygenin-labeled cRNA probes (Struhle et al. 1994).

\section{Generation and histological analysis of transgenic mice}

The vector $\mathrm{pK} 14-\beta \mathrm{G}-\mathrm{LEF} 1$ was constructed by insertion of a 700-bp StuI-EcoRI DNA restriction fragment encompassing the rabbit $\beta$-globin intron I between the $2.5-\mathrm{kb}$ K14 promoter and 
the human LEFl cDNA. Transgenic mice were generated as described previously (Vassar et al. 1989), and mice harboring the transgene were identified by PCR analysis of ear DNA (Innis et al. 1990). Mice testing positive were then checked for LEF1 expression by in situ hybridization analyses. For histology, tissues were placed in Bouin's fixative, embedded in paraffin, and sectioned $(5 \mu \mathrm{m})$. Tissues were stained with hematoxylin and eosin or toluidine blue.

\section{Acknowledgments}

We thank Dr. Brian Aneskievich, Dr. Panos Kouklis, Zhao-hui Yang, and Yiu-mo Chan for their thoughtful suggestions and advice. We thank Chuck Wellek, Phil Galiga, and Carl Hansen for their assistance in artwork and computer-assisted presentation of the data and Dr. Qian-Chun Yu and Andrew Syder for their assistance in printing. We thank Linda Degenstein, Alice Shen, and Debra Dugger for generating the transgenic mice described in this article. We thank Paul Gardener for oligonucleotide synthesis, and Maureen Boo and her staff associates in Surgical Pathology for technical assistance in histology. We also thank Dr. Rudy Grosschedl (University of California, San Francisco, CA) for his gift of LEF-1 polyclonal antiserum, Dr. Margaret Baron (Harvard University, Boston, MA) for her protocol of tissue nuclear extract preparations, Dr. Mark Roth (University of Michigan, Ann Arbor, MI) for his protocol for isolating mRNAs from plucked hairs, and Jurgen Schweizer (German Cancer Center, Heidelberg, Germany) for his gift of mouse K14 cDNA. E.F. is an investigator of the Howard Hughes Medical Institute. This work is supported by a grant from the National Institutes of Health (AR31737).

The publication costs of this article were defrayed in part by payment of page charges. This article must therefore be hereby marked "advertisement" in accordance with 18 USC section 1734 solely to indicate this fact.

\section{References}

Aneskievich, B.J. and E. Fuchs. 1992. Terminal differentiation in keratinocytes involves positive as well as negative regulation by retinoic acid receptors and retinoid $X$ receptors at retinoid response elements. Mol. Cell. Biol. 12: 4862-4871.

Byrne, C. and E. Fuchs. 1993. Probing keratinocyte and differentiation specificity of the $\mathrm{K} 5$ promoter in vitro and in transgenic mice. Mol. Cell. Biol. 13: 3176-3190.

Byrne, C., M. Tainsky, and E. Fuchs. 1994. Programming gene expression in developing epidermis. Development 120: 2369-2383.

Carlsson, P., M.L. Waterman, and K.A. Jones. 1993. The hLEF/ TCF- $1 \alpha$ HMG protein contains a context-dependent transcriptional activation domain that induces the TCR $\alpha$ enhancer in T cells. Genes \& Dev. 7: 2418-2430.

Conlan, R.A. and J. Rossant. 1992. Exogenous retinoic acid rapidly induces anterior ectopic expression of murine Hox-2 genes in vivo. Development. 116: 357-368.

Faus, I., H.-J Hsu, and E. Fuchs. 1994. Oct6: A regulator of keratinocyte gene expression in stratified squamous epithelia. Mol. Cell. Biol. 14: 3263-3275.

Giese, K. and R. Grosschedl. 1993. LEF-1 contains an activation domain that stimulates transcription only in a specific context of factor-binding sites. EMBO J. 12: 4667-4676.

Giese, K., A. Amsterdam, and R. Grosschedl. 1991. DNA-binding properties of the HMG domain of the lymphoid-specific transcriptional regulator LEF-1. Genes \& Dev. 5: 2567-2578.

Giese, K., J. Cox, and R. Grosschedl. 1992. The HMG domain of lymphoid enhancer factor 1 bends DNA and facilitates assembly of functional nucleoprotein structures. Cell 69: 185195.

Hardy, M. 1992. The secret life of the hair follicle. Trends Genet. 8: 159-166.

Heid, H.W., E. Werner, and W.W. Franke. 1986. The complement of native alpha-keratin polypeptides of hair-forming cells: A subset of eight polypeptides that differ from epithelial cytokeratins. Differentiation 32: 101-119.

Innis, M.A., D.H. Gelfand, J.J. Sninsky, and T.J. White. 1990. PCR protocols: A guide to methods and applications. Academic Press, San Diego, CA.

Jahoda, C.A., K.A. Horne, and R.F. Oliver. 1984. Induction of hair growth by implantation of cultured dermal papilla cells. Nature 311: 560-562.

Kaytes, P.S., A.R. NcNab, T.J. Rea, V. Groppi, T.T. Kawabe, A.E. Buhl, A.P. Bertolino, N.T. Hatzenbuhler, and G. Vogeli. 1991. Hair-specific keratins: Characterization and expression of a mouse Type-I keratin gene. I. Invest. Dermatol. 97: 835-842.

Kopan, R. and E. Fuchs. 1989. A new look into an old problem: Keratins as tools to investigate determination, morphogenesis, and differentiation in skin. Genes \& Dev. 3: 1-15.

Leask, A., M. Rosenberg, R. Vassar, and E. Fuchs. 1990. Regulation of a human epidermal keratin gene: Sequences and nuclear factors involved in keratinocyte-specific gene regulation. Genes \& Dev. 4: 1985-1998.

Mackenzie, A., M.W.J. Ferguson, and P.T. Sharpe. 1992. Expression patterns of the homeobox gene, Hox- 8 , in the mouse embryo suggest a role in specifying tooth initiation and shape. Development 115: 403-420.

McNab, A.R., L. Wood, N. Theriault, T. Gierman, and G. Vogeli. 1989. An ultra-high sulfur keratin gene is expressed specifically during hair growth. I. Invest. Dermatol. 92: 263266.

McNab, A.R., P. Andrus, T.E. Wagner, A.E. Buhl, D.J. Waldon, T.T. Kawabe, T.J. Rea, V. Groppi, and G. Vogeli. 1990. Hairspecific expression of chloramphenicol acetyltransferase in transgenic mice under the control of an ultra-high-sulfur keratin promoter. Proc. Natl. Acad. Sci. 87: 6848-6852.

Mina, M. and E.J. Kollar. 1987. The induction of odontogenesis in non-dental mesenchyme combined with early murine mandibular arch epithelium. Arch. Oral Biol. 32: 123-127.

Oosterwegel, M., M. van de Wetering, J. Timmerman, A. Kruisbeek, O. Destree, F. Meijlink, and H. Clevers. 1993. Differential expression of the HMG box factors TCF-1 and LEF-1 during murine embryogenesis. Development 118: 439-448.

Powell, B.C., A. Nesci, and G.E. Rogers. 1991. Regulation of keratin gene expression in hair follicle differentiation. Ann. N.Y. Acad. Sci. 642: 1-20.

Powell, B., L. Crocker, and G.E. Rogers. 1992. Hair follicle differentiation: Expression, structure and evolutionary conservation of the hair type II keratin intermediate filament gene family. Development 114: 417-433.

Rochat, A., K. Kobayashi, and Y. Barrandon. 1994. Location of stem cells of human hair follicles. Cell 76: 1063-1073.

Rogers, G.E. and B.C. Powell. 1993. Organization and expression of hair follicle genes. I. Invest. Dermatol. 101: 50S-55S.

Sengel, P. 1976. Morphogenesis of skin. Cambridge University Press, Cambridge, London, UK.

Struhle, U., P. Blader, J. Adam, and P.W. Ingham. 1994. A simple and efficient procedure for non-isotopic in situ hybridization to sectioned material. Trends Genet. 10: 75-76.

Travis, A., A. Amsterdam, C. Belanger, and R. Grosschedl. 1991. LEF-1, a gene encoding a lymphoid-specific protein with an HMG domain, regulates T-cell receptor $\alpha$ enhancer function. 
Genes \& Dev. 5: 880-894.

Trepicchio, W.L., M.A. Dyer, and M.H. Baron. 1994. A novel developmental regulatory motif required for stage-specific activation of the $\epsilon$-globin gene and nuclear factor binding in embryonic erythroid cells. Mol. Cell Biol. 14: 3763-3771.

Vainio, S., I. Karavanova, A. Jowett, and I. Thesleff. 1993. Identification of BMP-4 as a signal mediating secondary induction between epithelial and mesenchymal tissues during early tooth development. Cell 75: 45-58.

van de Wetering, M., M. Oosterwegel, D. Dooijes, and H. Clevers. 1991. Identification and cloning of TCF-1, a T lymphocyte-specific transcription factor containing a sequence-specific HMG box. EMBO I. 10: 123-132.

van de Wetering, M., M. Oosterwegel, F. Holstege, D. Dooyes, R. Suijkerbuijk, A.G. van Kessel, and H. Clevers. 1992. The human $T$ cell transcription factor-1 gene. Structure, localization, and promoter characterization. I. Biol. Chem. 267: 8530-8536.

van Exan, R.J. and M. H. Hardy. 1980. A spatial relationship between innervation and the early differentiation of vibrissa follicles in the embryonic mouse. J. Anat. 131: 643-656.

van Genderen, C., R.M. Okamura, I. Farinas, K-G. Quo, T.G. Parslow, L. Brahn, and R. Grosschedl. 1994. Development of several organs that require inductive epithelial-mesenchymal interactions is imparied in LEF-1-deficient mice. Genes \& Dev. 8: 2691-2703.

Vassar, R., M. Rosenberg, S. Ross, A. Tyner, and E. Fuchs. 1989. Tissue-specific and differentiation-specific expression of a human K14 keratin gene in transgenic mice. Proc. Natl. Acad. Sci. 86: 1563-1567.

Waterman, M.L., W.H. Fischer, and K.A. Jones. 1991. A thymusspecific member of the HMG protein family regulates the human $\mathrm{T}$ cell receptor $\mathrm{C} \alpha$ enhancer. Genes \& Dev. 5: 656669.

Wu, Y.-J. and J.G. Rheinwald. 1981. A new small, (40 kd) keratin filaments protein made by some cultured human cell carcinomas. Cell 25: 627-635.

Zhou, P., M.S. Szczypka, T. Sosinowski, and D.J. Thiele. 1992. Expression of a yeast metallothionein gene family is activated by a single metalloregulatory transcription factor. Mol. Cell. Biol. 12: 3766-3775. 


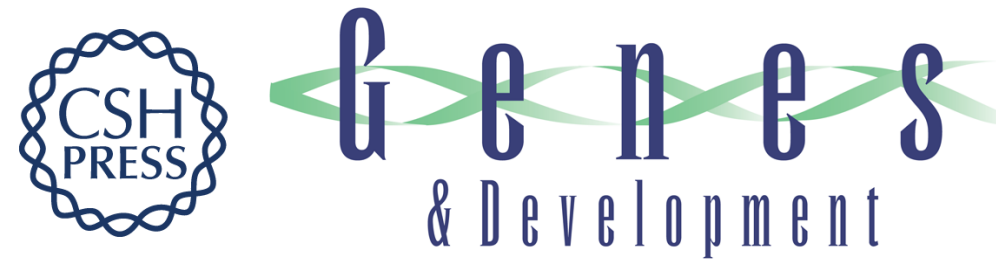

\section{Lymphoid enhancer factor 1 directs hair follicle patterning and epithelial cell fate.}

P Zhou, C Byrne, J Jacobs, et al.

Genes Dev. 1995, 9:

Access the most recent version at doi:10.1101/gad.9.6.700

References This article cites 36 articles, 19 of which can be accessed free at:

http://genesdev.cshlp.org/content/9/6/700.full.html\#ref-list-1

License

Email Alerting

Service

Receive free email alerts when new articles cite this article - sign up in the box at the top right corner of the article or click here.

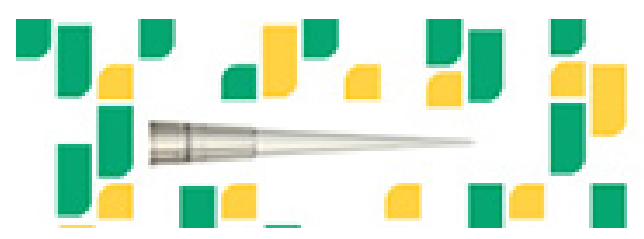

Focused on your science.

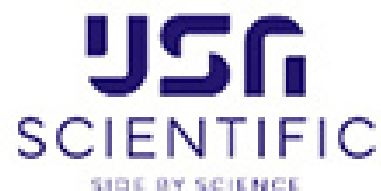

Copyright (c) Cold Spring Harbor Laboratory Press 